\title{
Singularidades Químico-Farmacêuticas da Ficção Queirosiana (2 ${ }^{\underline{a}}$ PARTE)
}

\author{
João Manuel Costa ${ }^{1}$, João Paulo André2* \\ ${ }^{1}$ Escola Secundária de Santa Comba Dão \\ 2 Departamento/Centro de Química, Universidade do Minho, Braga \\ jandre@quimica.uminho.pt
}

\begin{abstract}
D a análise efectuada à presença e ao papel da Química e da Farmácia na escrita realista de Eça de Queirós, resultou uma primeira parte deste artigo, que inclui as secções “Águas minerais e antiácidos” e "Metais pesados”. Nesta segunda parte, apresentam-se as secções "Fármacos e preparações de origem vegetal”, “Óleos, solventes e produtos resinosos” e "Outros fármacos e produtos químicos”.
\end{abstract}

\subsection{FÁrmacos e PREPARAÇõES de ORIGEM VEGETAL}

São vários os fármacos de origem vegetal ao longo da narrativa de Eça de Queirós. Comecemos pelos alcalóides opiáceos encontrados n’ Os Maias: o xarope de codeína que Miss Sarah, por recomendação de Carlos, tinha de tomar “de três em três horas”, e o láudano que o próprio Carlos chega a equacionar tomar para se suicidar ("Assim escorregou ao pensamento da morte. Ela seria a perfeita cura, o asilo seguro. Porque não iria ao seu encontro? Alguns grãos de láudano nessa noite e penetrava na absoluta paz...”). O láudano é também referido n’ O Primo Basílio, a propósito de Jorge que "Foi reler todas as cartas que ela lhe escrevera para o Alentejo, procurando descobrir nas palavras sintomas de frieza, a data da traição! Tinha-lhe ódio então, voltavam-lhe ao cérebro ideias homicidas - esganá-la, dar-lhe clorofórmio, fazer-lhe beber láudano!”.

O láudano era uma tintura de ópio com uma formulação que remontava a 1760, da autoria do médico inglês Thomas Sydenham, e que para além do ópio incluía ainda canela, cravinho e açafrão em vinho ou álcool etílico. Os médicos europeus recomendaram-no, pelo menos, até meados do século XIX [1].

O ópio, como se viu (1. ${ }^{a}$ parte), é referido duas vezes n’ $O$ Mistério da Estrada de Sintra e uma vez n’ O Mandarim (“no pátio [...] só ficara um velho, bêbedo de ópio, caído a um canto como um fardo.”).

A codeína (Figura 10A) é um dos alcalóides principais do ópio (o látex seco obtido das cápsulas da papoila-dormideira, a Papaver somniferum), possuindo uma forte actividade anti-tússica. N' A Ilustre Casa de Ramires encontra-se uma alusão sarcástica a um certo xarope peitoral de James: "Revelar Portugal, vulgarizar Portugal. Sim, amiguinho! Organizar, com estrondo, o reclamo de Portugal, de modo que todos o conheçam - ao menos como se conhece o Xarope Peitoral de James, hem? E que todos o adoptem - ao menos como se adoptou o sabão do Congo, hem?”. Trata-se de um xarope que, na época, era usado para a tosse e bronquites (repare-se no anúncio que uma antiga farmácia de Lisboa fazia ao produto - Figura 11); deveria conter codeína e provavelmente seria o xarope de Miss Sarah.

A morfina (Figura 10B), outro alcalóide do ópio, possui intensa actividade analgésica, a qual pode ser acompanhada da sensação de euforia e de bem-estar passageiros; igualmente origina sonolência (vide $O$ Mandarim) e cria dependência [2].

N’A Tragédia da Rua das Flores, ao Marinho adoentado, o Carvalhosa recomenda: “E beladona, beladona!”. A beladona (Atropa beladona) é uma herbácea existente em várias regiões do globo, incluindo Portugal, desde há muito conhecida pelos seus efeitos tóxicos. A toxicidade advém dos seus elevados teores em hiosciamina e escopolamina (Figura 10C). As moléculas destes dois alcalóides tropânicos exibem isomerismo óptico, sendo o isómero levo-rotatório (-) a forma biologicamente mais activa, ligando-se preferencialmente aos receptores de acetilcolina, inibindo a acção deste neuro-transmissor [3-5]. Podem, no entanto, ser usadas preparações galénicas das folhas da beladona, de forma a diminuir espasmos e cólicas gastrointestinais e biliares [2]. O medicamento actual Buscopan, um anti-espasmódico, é o derivado butilado da escopolamina [6]. N’ O Primo Basílio, o desmaio de Juliana (a criada de Luísa) - devido a uma síncope cardíaca, como explica Julião - é pouco duradouro: "mesmo antes que Joana atarantada, em cabelo, corresse à botica por um antiespasmódico, Juliana voltava a si, muito fraca.” O antiespasmódico seria, sem margem de dúvida, a beladona.

N’ O Primo Basílio podemos ainda encontrar outro alcalóide, o quinino que, conjuntamente com a digitalis, Juliana tomava para a insuficiência cardíaca: "Enfim, mesmo a engomar roupa se pode tomar digitalis ou quinino; mas é que o verdadeiro tratamento é o repouso, é a absoluta exclusão da fadiga. Que ela um dia se zangue ou que tenha uma manhã de canseira, e pode ir-se!”, alertava Julião.

O quinino propriamente dito é o sulfato de quinina, sendo esta (Figura 10D) um alcalóide anti-malárico isolado da casca da Cinchona officinalis, originalmente trazida 


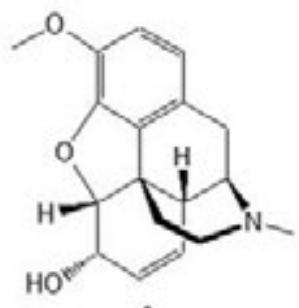

A

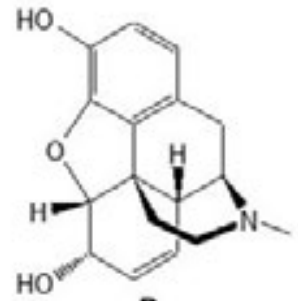

B<smiles>CN1[C@H]2CC[C@@H]1CC(OC(=O)[C@H](CO)c1ccccc1)C2</smiles><smiles>C=C1C(=O)O[C@H]2C[C@H](C)[C@H]3C=CC(=O)[C@]3(C)[C@H](O)[C@@H]12</smiles>

$\mathbf{F}$<smiles>CN1[C]2CC[C]1C[C](OC(=O)[C@H](CO)c1ccccc1)C2</smiles>

C<smiles>C=CC1CN2CCC1C2[C@H](O)[C@H](O)c1ccnc2ccc(OC)cc12</smiles>

D

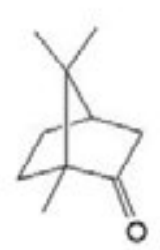

E<smiles>CC(C)(C#N)O[C@H]1OC(CO)[C@H](O)[C@H](O)[C@H]1O</smiles>

G

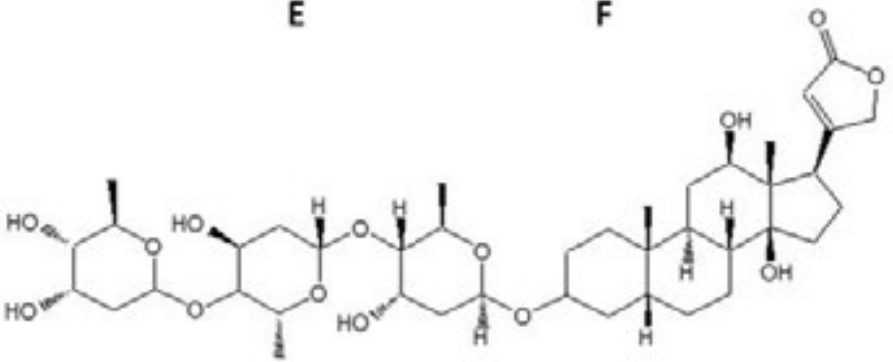

H

Figura 10 - Estruturas da codeína (A); morfina (B); escopolamina e hiosciamina (C); quinina (D); cânfora (E); helenalina (F), linamarina (G); digoxina (H)

da América do Sul para a Europa pelos navegadores espanhóis. Os farmacêuticos franceses Pelletier e Caventou isolaram e identificaram o alcalóide em 1820 [2]. ${ }^{1}$

O quinino não seria um fármaco adequado à condição clínica de Juliana, dado não ser de paludismo que sofria ("As feições miúdas, espremidas, tinham a amarelidão de tons baços das doenças do coração").

Digitalis é o género a que pertencem mais de vinte espécies de dedaleiras, planta floral bem conhecida em Portugal. Só duas, no entanto, possuem interesse terapêutico, a Digitalis purpurea e a Digitalis lanata, devido aos vários glicosídeos cardiotónicos que contêm e que constituem um grupo de fármacos usados no tratamento de arritmia e insuficiência cardíacas; destes, a digoxina (Figura 10H) é um dos mais importantes [2]. Estes glicosídeos são fortes inibidores, e altamente específicos, da $\mathrm{Na}^{+} \mathrm{K}^{+}$-ATPase. O uso terapêutico da digitalis não constituía uma novidade para a época em que $O$ Primo Basílio foi publicado (1878) pois já tinha

\footnotetext{
${ }^{1}$ O médico naval português Bernardino António Gomes (1768 - 1823) isolou a cinchonina, um outro alcalóide da casca da Cinchona officinalis. Este seu trabalho, publicado em 1812, teve algum impacto na comunidade científica internacional. Apesar de Pelletier e Caventou terem confirmado, posteriormente, que a recristalização da cinchonina pura realizada por Gomes constituía o isolamento do primeiro alcalóide puro, não deixaram de o criticar por não ter reconhecido a natureza básica deste composto. Gomes, todavia, verificou que a cinchonina pode ser dissolvida em ácido sulfúrico diluído e re-precipitada a partir desta solução pela adição de carbonato de potássio [http://www.spq.pt/ docs/Biografias/BAGomesport.pdf].
}

sido demonstrado em 1785, pelo médico britânico William Withering, que as folhas da Digitalis purpurea possuem propriedades cardio-estimuladoras [7].

N'A Relíquia encontramos duas alusões à arnica, uma herbácea da família das Asteraceae à qual também pertence o girassol. Várias espécies, como a Arnica montana e a Arnica chamissonis, contêm helenalina (Figura 10F), uma lactona sesquiterpénica com propriedades anti-inflamatórias que entra na composição de muitos preparados anti-inflamatórios de uso externo, destinados sobretudo ao tratamento de contusões e à cicatrização de ferimentos superficiais [8,9].

Um dos momentos mais hilariantes d' A Relíquia ocorre quando Raposão, que espreitava uma donzela pelo bura-

\section{XAROPE PEITORAL JAMES}

Nao ha tosse por mais antiga que seja que the resista, tem feito curas extraordinatias o c muito empregado nos casos de bronquites cro. nicas, ete., ete.

$$
\text { cooooo }
$$

Depósito Ceral,

Farmácia FraNCO, FILHOS

R de Belem, 18-22 - USBon

Figura 11 - Anúncio ao xarope peitoral de James 
ca da fechadura, é fortemente pontapeado pelo pai desta. O próprio Raposão descreve o que se passou a seguir: " $E$ muito digno, coxeando, voltei ao quarto a fazer pacientes fricções de arnica. Assim eu passei a minha primeira noite em Sião.”. Anteriormente, já nos tinha informado que “ia prevenido com remédios para o caso de um contratempo intestinal nesses descampados bíblicos...”; “Até linhaça, até arnica!...”.

N’ O Primo Basílio é-nos dito que D. Felicidade “inundava-se de arnica”: “Tinha uma luxação simples; nos quartos da Silveira, com o pé em compressas de arnica, cheia de terror de perder a perna, passava o dia rodeada de amigas, chorando-se, saboreando os mexericos do recolhimento, e debicando petiscos.”. N' O Crime do Padre Amaro, quando Amaro visitava o colega Natário, acamado com uma fractura, “enjoava-o o aspecto do quarto - impregnado dum cheiro de arnica e de suor, com uma profusão de trapos ensopados em malgas vidradas”. N' Os Maias, o romance de Raquel Cohen com João da Ega termina com a sova que leva do marido, o mesmo que, de seguida, carinhosamente, lhe aplica arnica: "levava a sova, deitava-se depois com o marido, e ele mesmo, decerto arrependido, chamando-lhe nomes doces, a ajudava, em ceroulas, a fazer as aplicações de arnica! Aquilo acabava em arnica!”.

A linhaça que o Raposão levava na mala na viagem à Terra Santa, aparece também referida por diversas vezes nas lides farmacêuticas de Artur n’ A Capital. Linhaça é a designação dada às sementes do linho (Linum usitatissimum). Na composição das sementes existem mucilagens com poder laxativo e emoliente, e óleo com propriedades igualmente emolientes e dermatológicas. A farinha das sementes era aplicada sob a forma de cataplasma em furúnculos, abcessos ou adenites. Na linhaça existe ainda linamarina (Figura 10G), um glicosídeo cianogénico tóxico [2].

N’ A Tragédia da Rua das Flores é-nos dada a seguinte descrição do quarto em que o Marinho se encontrava adoentado: "a mesa-de-cabeceira coberta de garrafas do médico, ... O quarto cheirava a cânfora...”. N’ A Capital, a convalescença do Sr. Abílio Pimenta, sob "ameaças de dores reumáticas”, foi “À custa de muito álcool canforado... - explicou ele com bonomia. - Foi a minha senhora que me curou. Nada de médicos, dizia-me ela. Tens dores nas cruzes? Fricções de álcool”. O odor a cânfora no Ramalhete desabitado é referido igualmente n’ Os Maias.

A cânfora é uma cetona terpénica (Figura 10E) existente na canforeira (Laurus camphora); é sólida à temperatura ambiente mas por sublimação liberta um forte aroma característico. Dissolvida em álcool etílico origina o álcool canforado, usado para inalações e fricções. A sua rápida evaporação sobre a pele deixa uma sensação de frescura, idêntica à do mentol [2].

N' O Crime do Padre Amaro, encontra-se uma curiosa alusão a um produto que era utilizado na época para a produção de "vinho a martelo". Tal acontece quando o Tio Osório, dono de uma casa de pasto em Leiria, diz que achava
Gustavo, amigo de João Eduardo, “mais magrito... Havia de ser das más águas de Lisboa e do muito pau campeche nos vinhos...”. A mesma alusão ao pau-campeche é encontrada nas Crónicas de Londres, quando Eça nos relata as movimentações militares da Rússia na Europa e na Ásia Menor. Não resistindo a abdicar da sua veia irónica, escreve: “Outros actos desagradáveis têm sido praticados no exército russo: assim o comissário-geral dos Fornecimentos acaba de ser fuzilado sem processo. Este funcionário estimável introduziu na farinha tal quantidade de cal - que realmente não era possível deixar de lhe meter algumas balas no peito. Uma certa quantidade de cal na farinha, como uma certa quantidade de pau campeche no vinho - são procedimentos razoáveis, que dão honra, grandes proveitos e ordinariamente uma condecoração. Mas uma tal porção de cal que torna a farinha mais própria para pintar paredes que para fazer pão é realmente abusivo, e o Conselho de Guerra foi apenas justo dando àquele funcionário uma disponibilidade... na eternidade."

O pau-campeche (Figura 12) é a madeira da árvore Haematoxylum campechianum, nativa do México e da América Central, da qual se obtém um corante vermelho vivo, a hemateína (Figura 13B), usado no passado em tinturaria, bem como na coloração de vinhos adulterados [10].

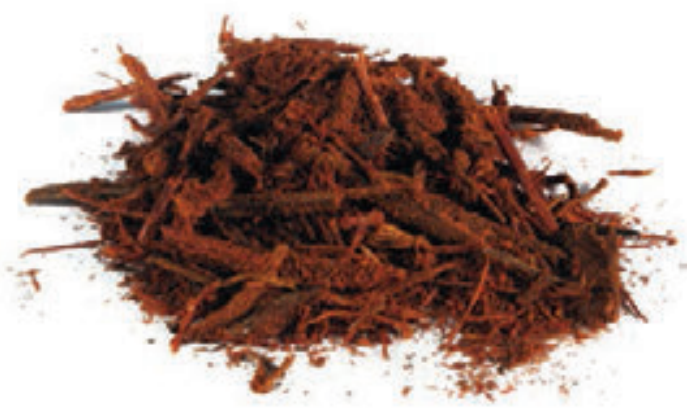

Figura 12 - Pau-campeche

Outro corante vegetal que aparece em Eça é a hena, ao descrever-nos, n’ O Egipto - Notas de Viagem, o bazar das drogas do Cairo: "Frutas secas, pastéis, drogas, tudo ali se reúne em confusão. As coisas estão em montes, em cima de papéis ou dentro de caixas sem tampa ou de sacos abertos; amontoa-se indiferentemente o henné, o antimónio, o pistache, o âmbar escuro², o mastik, a noz moscada, as tâmaras, a canela! Tudo aquilo é imundo!”.

A hena (Lawsonia inermis) é um arbusto muito comum no Norte de África, no Médio Oriente e na Índia. A sua casca

\footnotetext{
2 O âmbar escuro a que Eça se refere deverá ser o âmbar cinzento, ou ambergris, um material que tem origem no cachalote. Estes animais produzem no tracto gastrintestinal um triterpeno, a ambreína, que uma vez excretado no mar, sofre uma série de reacções de degradação por exposição ao sal, ar e luz solar, que acabam por originar uma mistura complexa de várias substâncias, conhecida por ambergris, com odor agradável. É um material gorduroso que pode ser encontrado flutuando no mar, acabando por vezes por dar à costa em agregados que chegam a atingir $100 \mathrm{~kg}$. Foi utilizado em perfumaria desde tempos remotos mas actualmente, para esse fim, recorre-se a substitutos de síntese [C. S. Sell (ed.), “The Chemistry of Fragances - From Perfumer to Consumer”, RSC, Cambridge, 2006]
} 
e as folhas secas são ricas em lawsona (Figura 13C), uma naftoquinona que em meio alcalino tem uma cor vermelho-alaranjada intensa. Para além de ser usada em cosmética, essencialmente para tingir o cabelo e para tatuagens da pele, a lawsona contém também propriedades antifúngicas que justificam a sua utilização em doenças dermatológicas [2].

Finalmente referimos a tília (Tilia cordata, T. platyphyllus, T. vulgaris), cuja inflorescência possui flavonóides com propriedades ansiolíticas e sedativas [2,11] e que, em Eça, aparece n’ O Crime do Padre Amaro não só como elemento cenográfico ("uma fresca folhagem de tília que roçava o peitoril da janela”), como também através da alusão à respectiva infusão: "Um chá de tília alivia-o às vezes... Mas por desgraça hoje nem tília tenho! Ai, Jesus! Amaro correu a casa a buscar tília”, para logo de seguida D. Josefa agradecer: "Muito agradecida, senhor pároco, dizia D. Josefa. Rica tília! É de muita caridade. Ele agora naturalmente cai em sonolência.”.

\section{4. Óleos, solventes e produtos resinosos}

No conjunto da narrativa queirosiana, para além do azeite, sobressaem as referências a dois outros óleos: o de amêndoas doces e o de rícino. O óleo de amêndoas é obtido por prensagem das sementes maduras da amendoeira (Prunus dulcis), sendo constituído por uma variedade de ácidos gordos. Pode ser usado directamente nas inflamações da pele e como protector solar sendo, por isso, muito comum na indústria cosmética [2]. N’ O Primo Basílio, Eça recorre a este óleo para o retrato físico de Joana, a cozinheira de Luísa e Jorge: "Era uma rapariga muito forte, com peitos de ama, o cabelo como azeviche, todo lustroso do óleo de amêndoas doces”.

N’ O Primo Basílio surge também o óleo de rícino; em forma de comparação, Leopoldina menciona-o a Luísa: "É como quem toma óleo de rícino! - disse a outra com um gesto cínico. E acrescentou, vendo o horror de Luísa: - Que diabo! Onde é que está a desonra, em pedir dinheiro emprestado? Todo o mundo pede...'. N' O Conde d'Abranhos, a alusão ao óleo de rícino é feita com o intuito de ridicularizar um membro do governo: "o Ministro das Obras Públicas, batendo-se em duelo, não vomitara, mas tivera um tão vergonhoso contratempo intestinal, que fora necessário conduzi-lo a uma venda próxima, onde, durante horas, o prostrado estadista circulou lividamente de um banco da cozinha para um recanto do pátio, como sob a influência dissolvente de óleo de rícino tomado sem discernimento!”. N’ A Cidade e as Serras, este óleo é igualmente referido de forma metafórica: "Logo nessa manhã (com uma actividade em que eu reconheci a pressa enjoada de quem bebe óleo de rícino) escreveu ao Silvério mandando caiar, assoalhar, envidraçar o casarão".

O óleo de rícino é obtido a partir das sementes da Ricinus communis, uma planta das regiões tropicais e subtropicais [8]. É fundamentalmente constituído por ricinoleína (Figura 13A), o éster glicérico do ácido ricinoleico. O efeito purgativo do óleo de rícino é devido à acção irritante do ácido ricinoleico sobre a mucosa intestinal, sendo este produzido através da hidrólise enzimática da ricinoleína.

No que respeita a solventes, existe na ficção de Eça uma variedade considerável: álcool, clorofórmio, éter, benzina,

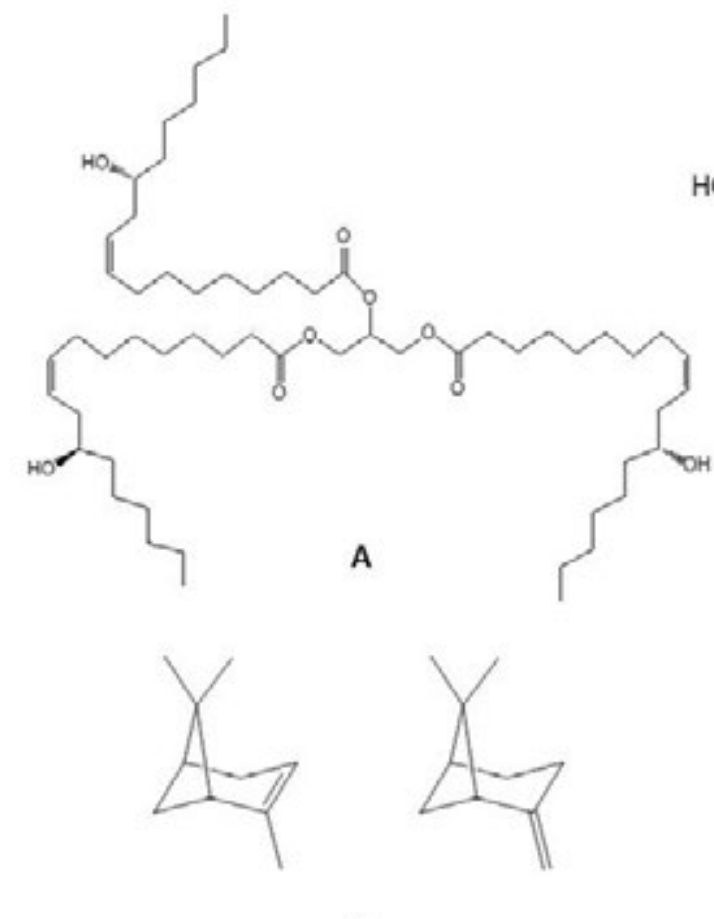

D<smiles>O=C1C=C2CC3(O)COc4c(ccc(O)c4O)C3=C2C=C1O</smiles>

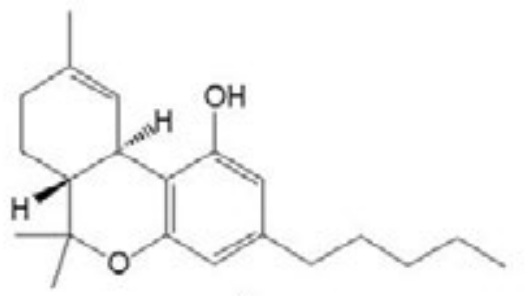

E

Figura 13 - Estruturas da ricinoleína (A); hemateína (B); lawsona (C); $\alpha$ - e $\beta$-pineno (D); $\Delta_{9}$-tetra-hidrocanabinol (E) 
aguarrás, terebintina.... O éter refere-se ao éter dietílico, solvente comum em Química Orgânica e utilizado como agente anti-séptico em hospitais. $\mathrm{O}$ éter dietílico foi, em 1842, o primeiro agente anestésico a que a medicina recorreu, afigurando-se, assim, algo duvidosa a escolha deste solvente n’ O Primo Basílio para a reanimação de Luísa, após o desmaio provocado pela visão da carta de Basílio ("Felizmente havia éter, fizeram-lho respirar; apenas abriu lentamente os olhos, Jorge precipitou-se sobre ela”) [12].

Em Civilização e n’ A Cidade e as Serras, Eça dá ao éter um destino menos comum: a gastronomia em casa de Jacinto. Assim, em Civilização encontramos: “A sua sopa de alcachofra e ovas de carpa; os seus filetes de veado macerados em velho Madeira com puré de nozes; as suas amoras geladas em éter”. Por seu lado, n’ A Cidade e as Serras aparece: "Depois saboreariam aqueles senhores um filete de veado, macerado em Xerez, com geleia de noz. E por sobremesa simplesmente laranjas geladas com éter" e ainda "morangos gelados em Champanhe e avivados dum fio de éter!”. Nestas passagens, como notou Marie-Hélène Piwnik [13], o éter possui um significado duplo ("prato simbólico"), contudo, como solvente, pode efectivamente arrefecer as frutas como consequência da sua grande volatilidade.

O clorofórmio é outro solvente comummente usado em Química Orgânica e que, apesar da sua toxicidade, que afecta sobretudo o fígado, foi também, a partir de 1848, utilizado como anestésico, uso esse que se estendeu até ao século XX [14]. N’ O Crime do Padre Amaro, a propósito do estado clínico de Amélia, a engomadeira Dionísia afirma ao abade Ferrão que "Estava indignada. O senhor doutor tinha torturado a criaturinha. Até lhe quisera administrar clorofórmio...”. N’ O Primo Basílio, como se viu, o traído Jorge, num assomo de ódio para com Luísa, pensou "esganá-la, dar-lhe clorofórmio, fazer-lhe beber láudano!”.

A benzina, também designada por éter de petróleo, é um solvente obtido da destilação do petróleo, e corresponde a uma mistura de vários hidrocarbonetos. Dado o seu elevado poder de dissolução de gorduras é, ainda hoje, usada para remover nódoas nas limpezas de roupa a seco. N' $O$ Conde d'Abranhos, como vimos, a sua menção constitui um exercício da mais fina ironia: "Este governo não há-de cair - porque não é um edifício. Tem que sair com benzina - porque é uma nódoa!”.

Os produtos resinosos são exsudatos de secreções de plantas, endurecidos por exposição ao ar, e que apresentam uma composição química complexa da qual os compostos terpénicos (ácidos resínicos, álcoois resínicos, resinóis e outros) são os mais representativos. Praticamente todos os produtos resinosos contêm óleos essenciais, podendo alguns deles conter gomas (designando-se nesse caso gomo-resinas). Se o exsudato resinoso contiver ácido benzóico ou ácido cinâmico, ou ésteres destes, designa-se por bálsamo.

Na obra de Eça, são abundantes as referências a vários destes produtos resinosos e aos seus derivados. Comecemos pela terebintina, um solvente obtido da destilação de óleo-resinas provenientes de árvores como a Pistacia terebinthus ou o pinheiro-bravo e constituído por terpenos, dos quais se destacam o $\alpha$ - e o $\beta$-pineno (Figura 13D) [2]. Em termos médico-farmacêuticos, a terebintina foi utilizada desde tempos remotos, sobretudo para aplicação tópica, tanto para fricções como para combater parasitas do corpo; quando misturada com gordura animal podia constituir unguentos para o peito ou inaladores para problemas nasais e de garganta. Exibe propriedades ligeiramente anti-sépticas e expectorantes, tendo sido usada no tratamento da bronquite crónica. No passado, a sua ingestão chegou a ser recomendada para combater parasitas intestinais. Alguns preparados farmacêuticos modernos contêm ainda terebintina na sua formulação [8].

N’ Os Maias, após o regresso de Carlos de Paris, é-nos assim descrito o Ramalhete: "No salão nobre os móveis de brocado, cor de musgo, estavam embrulhados em lençóis de algodão, como amortalhados, exalando um cheiro de múmia a terebintina e cânfora”. N' A Cidade e as Serras há também uma referência à terebintina a propósito de Jacinto que, apesar da sua vivência opulenta (ou devido a ela), acaba por soçobrar na mais profunda angústia: “Que maçada! E depois uma noite abominável, enrodilhada em sonhos... Tomei sulforal, chamei o Grilo para me esfregar com terebintina... Uma seca!”.

A aguarrás, também designada por essência de terebintina, é uma mistura líquida de vários compostos alifáticos, obtida através da destilação da terebintina, e constitui um bom solvente para tintas, ceras e vernizes. N' Os Maias, quando Ega se prepara para descrever os atributos físicos de Raquel Cohen, a amante, Carlos diz-lhe que não quer saber por Ega estar bêbedo, ao que este ironicamente retorquiu: "Bêbedo! Ele? Ora essa!... Era coisa que não podia, era empiteirar-se. Tinha feito o possível, bebido tudo, até aguarrás”.

Os bálsamos são amplamente mencionados por Eça, principalmente em sentido figurado, como por exemplo quando n’ O Crime do Padre Amaro o secretário-geral em Leiria diz ao padre Natário: "No fim de tudo a fé é a mola real da sociedade. Tome uma chávena de chá... Ah! é um grande bálsamo!...”. Perante a recusa do chá acrescentou: "Mas não! Quando digo um grande bálsamo refiro-me à fé, não ao chá! Ah! ah! É boa, não?”. Em sentido tout court encontramos n' O Suave Milagre as seguintes passagens: “atravessando numa barca para a terra dos Gerassénios, onde começava a colheita do bálsamo" e "No Poço de Jacob repousava uma larga caravana, que conduzia para o Egipto mirra, especiarias e bálsamos de Gileade”. Este último excerto, curiosamente, estabelece uma forte intertextualidade com o Génesis (37:25): “e eis que uma companhia de ismaelitas vinha de Gileade; e os seus camelos traziam especiarias e bálsamo e mirra, e iam levá-los ao Egipto.”.

O bálsamo de Gileade, produto gomo-resinoso também conhecido por bálsamo da Judeia ou bálsamo de Мeca, é obtido da Commiphora gileadensis (Commiphora opobalsamum), planta nativa do sul da Arábia mas cultivada 
nas terras de Israel desde a Antiguidade. No mundo greco-romano o seu perfume era altamente apreciado sendo também o que atingia os preços mais elevados. Seria este o bálsamo que a Bíblia várias vezes refere [15].

Em Eça, no domínio dos produtos resinosos, há ainda a destacar a mirra: "Porventura já algum grave rei do Oriente despertou, e olhou a estrela, e tomou a mirra nas suas mãos reais" (A Cidade e as Serras). N'A Relíquia a mirra aparece em passagens como "daquela multidão saía um cheiro morno de suor e de mirra”, “Topsius ainda parou entre as tendas dos perfumistas, (...) mas logo fugimos ao ardente cheiro que ali sufocava, vindo das resinas, das gomas dos países dos negros, dos molhos de plumas de avestruz, da mirra de Oronte, das ceras de Cirenaica, dos óleos rosados de Císico (...)" e "O essénio entregou a um dos escravos a trouxa, e o cesto que estava cheio de mirra e de ervas aromáticas”.

N’ O Mandarim há uma referência a "uma caixa de frascos de «Opoponax»...”. O opoponax (ou opopanax) é obtido da seiva da Opopanax chironium, da família das Apiaceae, e a mirra provém da seiva de plantas do género Commiphora, pertencentes à família das Burseraceae. São ambos ricos em polissacarídeos e proteínas, bem como numa variedade de óleos essenciais voláteis que lhes conferem a sua fragância particular, de acordo com a paleta de esteróides, esteróis e terpenos que apresentam. Por exemplo, a combustão do opoponax origina a libertação de um odor característico que faz lembrar o da alfazema [16]. Ao longo dos tempos estas gomo-resinas têm sido usadas como agentes perfumadores, tanto na forma de incensos (Figura 14) como de perfumes corporais, embora tenham também sido utilizadas para fins medicinais. Desde a Antiguidade que a mirra é um constituinte de incensos, embora o incenso propriamente dito seja o óleo-gomo-resina (contém teores mais elevados do óleo essencial) obtido de plantas como a Boswellia carterii, igualmente uma Burseraceae [17]. Estes produtos resinosos são actualmente usados em pastas dentífricas e na indústria da perfumaria. A mirra, devido às suas propriedades antibacterianas e antifúngicas, está ainda inscrita na Farmacopeia Portuguesa [2].

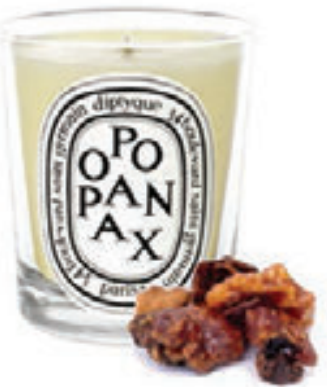

Figura 14 - Opoponax e vela aromática actual

As referências ao incenso são comuns na obra de Eça, sendo O Crime do Padre Amaro, por motivos óbvios, especialmente abundante nelas: "ramos bentos, palmas de mártires, cartuchinhos de incenso”; “o ar adensava-se já dos hálitos juntos e de um cheiro de incenso"; "Depois ele mesmo, de pé, no segundo degrau do altar, de mãos postas, foi incensado; o Pimenta vesgo fazia ranger galhardamente as correntes de prata do turíbulo; um perfume de incenso derramava-se, como uma anunciação celeste”; “recebendo o cheiro que ela trazia da igreja nos vestidos, impregnados de incenso e salpicados de água benta”; "toda a casa cheirava a cera e a incenso".

N' A Relíquia, encontramos a inesquecível descrição de como o Raposão iludia a sua devota tia: "Por isso agora as minhas precauções eram tão apuradas que, para evitar me ficasse na roupa ou na pele o delicioso cheiro da Adélia, eu trazia na algibeira bocados soltos de incenso. Antes de galgar a triste escadaria da casa, penetrava subtilmente na cavalariça deserta, ao fundo do pátio; queimava no tampo de uma barrica vazia um pedaço da devota resina; e ali me demorava, expondo ao aroma purificador as abas do jaquetão e as minhas barbas viris... Depois subia; e tinha a satisfação de ver logo a Titi farejar, regalada: - Jesus, que rico cheirinho a igreja!”. Nesta obra, podem ainda encontrar-se outras alusões a este produto associado ao divino, à evasão e ao misticismo: "os regalos de um altar, o incenso vivo das rosas” e "Queimai incensos e nardos”.

N'A Ilustre Casa de Ramires, de forma metafórica, encontramos a seguinte referência ao incenso: "E de entre as suas ameias, mais alto que da varanda, lhe parecia interessante respirar aquela rumorosa simpatia esparsa, que em torno, pelas freguesias rolava, subindo para ele, através da noite, como um incenso.”. N' Os Maias pode também ler-se: “E Ega acendeu um pouco de incenso em dois perfumadores de bronze."; "Pouco a pouco, o calor, o aroma do incenso, a exalação das flores, forçaram o Baptista a abrir uma das janelas do terraço.”; "Ega, depois de beber um gole de café, voltara ao escritório, onde o cheiro de incenso espalhava uma melancolia de capela.” e "Ainda errava um vago cheiro de incenso e de fenol.”. N’ O Primo Basílio, o incenso é igualmente mencionado: "recamado de ouro, entre instrumentações solenes e rolos de incenso!”, “sonhava com os incensos e os almíscares ${ }^{3}$ das florestas aromáticas” e "as asas do nariz dilatavam-se-lhe, como para respirar os incensos”. No conto A Perfeição, pode da mesma forma ler-se: "esta deserta imensidade do mar salgado em que se não encontram cidades de homens, nem templos cercados de bosques, nem sequer um pequenino santuário de onde suba o aroma do incenso".

\footnotetext{
3 O almíscar é um perfume de odor quente e intenso, extraído de uma glândula anal de animais como o cervo-almiscarado mas que também pode ser encontrado nalgumas espécies vegetais. O cheiro do almíscar animal deve-se ao indol e escatol (pouco agradáveis), a que se adicionam ainda a muscona e a civetona, conferindo-lhe o seu perfume característico, de notas doces e quentes. Tem sido usado na perfumaria desde tempos remotos mas actualmente é obtido por via sintética [C. S. Sell (ed.), "The Chemistry of Fragances - From Perfumer to Consumer”, RSC, Cambridge, 2006]. Eça também menciona o almíscar n’ A Relíquia: "uma senhora, grande e branca, com um rumor forte de sedas claras, espalhando um aroma de almíscar" e "Mas tranquilizado, decerto, pela minha face jucunda e material, pelas minhas luvas almiscaradas, pelo meu fútil raminho de violetas”. Aparece igualmente no conto Adão e Eva no Paraíso: "preguiçam pedregosos crocodilos, achatados sobre o ventre, que arfam molemente, escancarando as fundas goelas na tépida preguiça da tarde, embebendo todo o ar com um cheirinho de almíscar.”).
} 
O mástique, que faz parte do rol de produtos disponíveis no bazar das drogas do Cairo, tal como nos é relatado n' $O$ Egipto - Notas de Viagem, é uma gomo-resina de cor branca amarelada e semi-transparente (Figura 15), obtida da seiva da Pistacia lentiscus, árvore que é cultivada sobretudo na ilha grega de Quios. É utilizado em vernizes e como material de vedação em carpintaria. O seu sabor fresco a pinho e a cedro é muito apreciado nas doçarias da Grécia e da Turquia, em particular em gelados. Tem propriedades medicinais, nomeadamente no alívio dos sintomas de úlceras gástricas e duodenais [18].

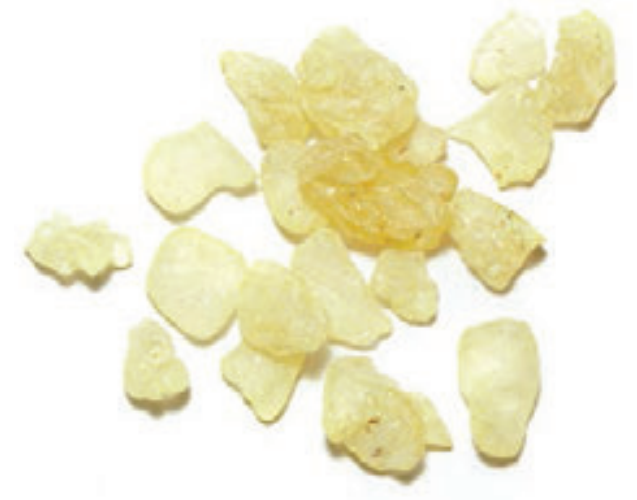

Figura 15 - Mástique

Ainda n’ O Egipto - Notas de Viagem, há uma curiosa referência ao haxixe: "Fomos uma única vez ao bazar das drogas: procurávamos hachisch. - Hachisch? - disse-nos Jonas Alli. - Mas é proibido! - Mas deve-o haver... sobretudo sendo proibido! - Em primeiro lugar - responde ele gravemente -, há três qualidades de hachisch: há hachisch em pastilhas... - Pois venham as pastilhas! - Há hachisch em bolo... - Pois venham os bolos! - Há hachisch em geleia... - Então, venha a geleia!.”

O haxixe (do árabe "hashish”) é o exsudato resinoso obtido a partir das brácteas (pequenas folhas) e das bractéolas das inflorescências do cânhamo-indiano e de outras variedades de Cannabis (caso da Cannabis sativa). São plantas ricas em canabinóides, sendo o $\Delta_{9}$-tetra-hidrocanabinol o constituinte mais psicoactivo (Figura 13E). As partes que são fumadas (folhas e flores), numa preparação idêntica à do tabaco, são geralmente designadas por marijuana ou liamba. O $\Delta_{9}$-tetra-hidrocanabinol tem acção analgésica e antiemética, sendo também usado como medicamento antiglaucoma [19, 20].

N’A Cidade e as Serras há referência ao âmbar: "Desde o berço, onde a avó espalhava funcho e âmbar para afugentar a Sorte-Ruim (...)” e "Ah! O âmbar e o funcho da Sra. D. Angelina tinham escorraçado do seu destino, bem triunfalmente e para sempre, a Sorte-Ruim!”. O âmbar é resina fossilizada e segundo as crenças populares tem o poder de atrair boa sorte, sendo por isso usado como amuleto. $\mathrm{N}^{\prime} A$ Relíquia encontramos a seguinte descrição: “e os tecidos bordados, os algodões de Galácia, os finos linhos de cores que as cingiam, ensopados nas essências ardentes de âmbar, de malobatro e de bácaris, enchiam o ar de fragrância e de moleza a alma dos homens”. O malóbatro era um óleo aromático citado desde a Antiguidade e a partir do qual se preparavam unguentos; crê-se poder ter sido obtido da Cinnamomum tamala, uma Laureaceae. O bácaris (Baccharis dracunculifolia) é um arbusto da família das Asteraceae, nativo da América do Sul e rico em óleos essenciais e ácido cafeico, a que são atribuídas propriedades antioxidantes e anti-inflamatórias [21,22].

\subsection{OUTROS FÁRMACOS E PRODUTOS QUÍMICOS}

O caso do “sulforal”, que Jacinto toma para a insónia n’ A Cidade e as Serras ("Tomei sulforal, chamei o Grilo para me esfregar com terebintina...”), é merecedor de alguma atenção. Com efeito, foi "sulforal” que saiu na primeira edição do romance, todavia existem algumas edições posteriores em que a designação do fármaco consta, correctamente, como "sulfonal”. O Sulfonal (Figura 16) foi efectivamente um fármaco que, pelas suas propriedades hipnóticas, foi adoptado em 1888 como indutor do sono [23].

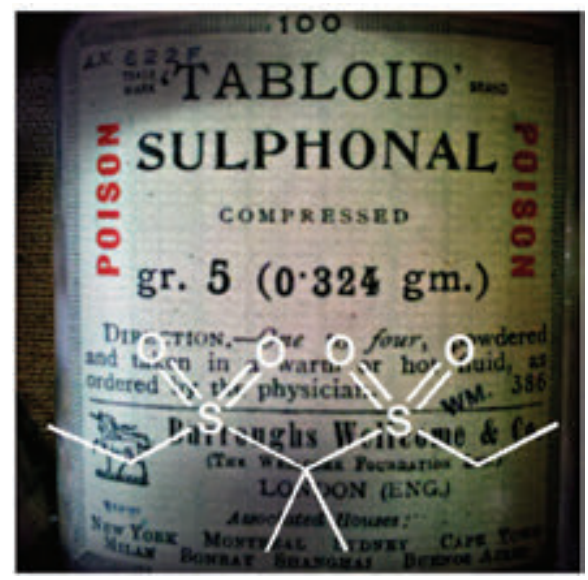

Figura 16 - Sulfonal

Por sua vez, o Sulforal é um antibiótico actual, de aplicação veterinária, que obviamente não existia no tempo de Eça (trata-se de uma sulfonamida, categoria de compostos que só apareceu a partir de 1932 [24]). Admite-se, assim, que Eça transcreveu mal a designação do fármaco, o que não deixa de ser compreensível, dada a similaridade fonológica de "sulforal” com "sulfuroso" e "sulfúrico”.

Os cheiros que, n’ Os Maias, Eça atribui ao Ramalhete, são variados. Carlos notou o aroma da terebintina e da cânfora mas Ega, ao recordar com nostalgia as felicidades ali passadas, notou que no ar "Ainda errava um vago cheiro de incenso e de fenol.” O fenol (ácido carbólico) foi originalmente obtido em 1834 pelo alemão Friedlieb Ferdinand Runge, a partir da destilação do alcatrão da queima da hulha. Em 1867, o médico britânico Joseph Lister foi pioneiro na utilização do fenol como agente anti-séptico nos procedimentos cirúrgicos e no pós-operatório, reduzindo drasticamente as mortes por infecção. A hulha (carvão mineral) foi usada em Londres desde 1814 para obtenção do gás da iluminação pública, que era constituído essencialmente por hidrogénio, metano e monóxido de carbono [24]. Posteriormente, a "novidade” também acabaria por chegar a Portugal, sendo o gás de iluminação objecto de vastas referências na obra de Eça. 
O nitrato de prata, outro produto químico patente na prosa queirosiana, é um sal que, sendo cáustico, era utilizado em Medicina como cauterizador para eliminação de verrugas e outras pequenas tumorações da pele e, por isso, também conhecido por "pedra infernal”. N' A Capital é referido de forma metafórica: "como tratamento externo, cautério de nitrato de prata” e "Portugal não deve ser reformado, como diz o Damião, deve ser queimado a nitrato de prata!...”.

N' O Mistério da Estrada de Sintra, após a enunciação de um rol de sintomas de fraqueza do narrador ("empalideceste”, "beiços brancos”, "vertigens”, "abuso de tabaco nas funções do coração”, “debilidade resultante da fome”, ....), encontramos: "Agora estás afogueado e vermelho como lacre: toma ferro e brometo.”. Com efeito, os brometos foram durante o séc. XIX usados como sedativos, em especial o brometo de potássio. No início do séc. XX usou-se, para o mesmo fim, o brometo de lítio, prática que foi abandonada na década de 40 devido ao considerável número de vítimas mortais que fatalmente o confundiam com o sal da cozinha. Os brometos, todavia, são ainda hoje usados em medicina veterinária. O ferro, por via oral, intramuscular ou endovenosa, é desde o séc. XIX utilizado para tratamento da anemia. A carência deste elemento químico pode provocar também distúrbios como anorexia, sensibilidade óssea, problemas digestivos, tontura ("vertigens" n' O Mistério da Estrada de Sintra ) e fadiga [25].

Os ácidos encontrados na obra de Eça são o oxálico e o prússico/cianídrico. Com uma dissolução do primeiro, limpava o sacerdote o seu candeeiro de latão n' O Conde d’Abranhos. Com efeito, o ácido oxálico é um composto bastante venenoso mas que, entre outras aplicações, é usado como produto anti-tártaro e na limpeza de metais e na remoção de ferrugem. As suas funções devem-se ao elevado poder quelante do ião oxalato. A sua toxicidade deve-se, consequentemente, à enorme tendência para complexar o ião cálcio, podendo baixar a concentração fisiológica deste ião para níveis críticos [26]. O ácido prússico é altamente venenoso pois corresponde a uma solução aquosa de cianeto de hidrogénio. A toxicidade do ião cianeto é provocada pela sua ligação à citocromo $a-a_{3}$ oxidase, inibindo a actividade enzimática desta. Como resultado, as células ficam privadas do uso de oxigénio e a produção de trifosfato de adenosina diminui drasticamente [5].

N' O Mistério da Estrada de Sintra já tinha sido encontrada a referência ao vinho "destemperado com ácido prússico” e n’ O Crime do Padre Amaro, o Carlos da botica, num rancor "farmacêutico" contra os republicanos, que logo se transforma num rancor "legalista”, afirma-se da seguinte forma: "Eu sou um homem pacífico, aqui a Amparozinho conhece-me bem; pois se eu tivesse de aviar uma receita para um republicano declarado, não tinha dúvida, em lugar de lhe dar uma dessas composições benéficas que são o orgulho da nossa ciência, de lhe mandar uma dose de ácido prússico... Não, não direi que lhe mandasse ácido prússico... mas se estivesse no banco dos jurados, havia de lhe fazer cair em cima todo o peso da lei!”. N' A Cidade a as Serras existem duas alusões ao ácido cianídrico: a primeira é a propósito do tédio parisiense de Jacinto ("Incessantemente aludia à morte como a uma libertação. Uma tarde mesmo, no melancólico crepúsculo da Biblioteca, antes de refulgirem as luzes, consideravelmente me aterrou, falando num tom regelado de mortes rápidas, sem dor, pelo choque de uma vasta pilha eléctrica ou pela violência compassiva do ácido cianídrico.”), a outra é para contextualizar a impaciência de Zé Fernandes que, por fim, desafiará Jacinto para partirem para Tormes (“Aturaria eu ainda aquele Príncipe palpando amargamente a caveira, e, quando o crepúsculo entristecia a Biblioteca, aludindo, num tom rouco, à doçura das mortes rápidas pela violência misericordiosa do ácido cianídrico?”).

É interessante notar algum cuidado na actualização da nomenclatura química empregue. Assim, enquanto n’ O Mistério da Estrada de Sintra e n’ O Crime do Padre Amaro há referência ao ácido prússico, n’ A Cidade e as Serras (obra póstuma e não totalmente revista pelo autor), já o mesmo composto é designado pelo nome que ainda hoje perdura: ácido cianídrico (uma actualização de outrem?).

\section{Considerações FinAIS}

Os abundantes aspectos químico-farmacêuticos patentes na obra de Eça de Queirós - enquadrados no retrato literário da sociedade contemporânea, na linha dos modelos de Gustave Flaubert e Émile Zola, onde nem sempre a "nudez forte da verdade" se encobre sob o "manto diáfano da fantasia” - podem perfilar com (ou mesmo dominar sobre) os detalhes narrativos inerentes a outros domínios do saber científico-natural (Botânica, Física, Hereditariedade) também encontrados na obra do autor. É de referir que nas suas Notas Contemporâneas (no texto Almanaques), Eça chegou a delinear um ensaio sobre a História da Ciência.

Por um lado, este manancial de saber, que resulta do dinamismo das Ciências Naturais, e da Química em particular, em finais de Oitocentos, credibiliza, pela verosimilhança, o retrato fidedigno da vida trivial e da domesticidade, em sintonia com os códigos estético-literários defendidos em 1871 na 4. ${ }^{\text {a }}$ Conferência do Casino de Lisboa ("[O Realismo] É a análise com o fito na verdade absoluta”). Por outro, dada a celeridade com que a Química progredia na época, Eça, esse cidadão culto e multifacetado, demonstrava ser um homem ao corrente do "melhor" que a civilização tinha para oferecer ao mundo, e a Portugal.

Assim, pelo rigor do traço realista, pelo pragmatismo dos esboços sociais, pelo cosmopolitismo do seu ideário estético-literário e pelo universalismo do saber científico, Eça garante a canonicidade da sua obra, ombreando com os mais destacados vultos da Literatura do seu tempo no espaço mítico que Goethe designou de Weltliteratur.

\section{Agradecimentos}

Os autores agradecem as frutuosas discussões com o Professor Jorge Calado, a gentil cedência de material bibliográfico por parte do Engenheiro Luís Ferro, a cuidada leitura crítica das colegas Ana Paula Esteves e Cláudia Cunha 
Pascoal, bem como as enriquecedoras sugestões dos revisores do manuscrito.

\section{REFERÊNCIAS}

[1] E. Raviña, "The Evolution of Drug Discovery”, WileyVCH, Weinheim, 2011

[2] A. Proença da Cunha, "Farmacognosia e Fitoquímica", Fundação Calouste Gulbenkian, Lisboa, 2009

[3] J. Thearle, J. Pearn, Hist. Sci. Med. 17 (1982) 257-261

[4] G. Grynkiewicz, M. Gadzikowska, Pharmacol. Rep. 60 (2008) 439-463

[5] J.P. André, J. Chem. Educ. 90 (2013) 352-357

[6] G.N. Tytgat, Drugs 67 (2007) 1343-1357

[7] E.L. Figueiredo, F.P. Machado, Insuficiência Cardíaca 5 (2010) 72-78

[8] C.K. Kokate, A.P. Purohit, S.B. Gokhale, "Pharmacognosy", Nirali Prakashan, Pune, 2008

[9] G. Lyß, A. Knorre, T.J. Schmidt, H.L. Pahl, I. Merfort, J. Biol. Chem. 27 (1998) 33508-33516

[10] A.M. Peixoto (ed.) “Enciclopédia Brasileira”, Editora da Universidade de S. Paulo, S. Paulo, 1998

[11] J. M. Calderón-Montaño, E. Burgos-Morón, C. PérezGuerrero, M. López-Lázaro, Mini-Reviews in Medicinal Chemistry 11 (2011) 298-344

[12] G.B. Rushman, N.J.H. Davies, R.S. Atkinson, “A Short History of Anaesthesia: The First 150 Years”, ButterworthHeinemann, Oxford, 1996
[13] M.H. Piwnik, in M.A. Ribeiro (coord.), "História Crítica da Literatura Portuguesa”, vol. VI, Editorial Verbo, Lisboa, 2000

[14] J. Wawersik, Anaesthesiol. Reanimation 22 (1997) 144-152

[15] D. Iluz, M. Hoffman, N. Gilboa-Garber, Z. Amar, J. Pharm. \& Pharmacol. 4 (2010) 516-520

[16] E.C. Pope, A. Ali, S.L. Conlan, I.D. Bowen, A.S. Clare, A.F. Rowley, Aquat. Biol. 4 (2008) 175-185

[17] L. O. Hanuš, T. Řezanka, V. M. Dembitsky, A. Moussaieff, Biomed. Papers 149 (2005) 3-28

[18] C. Koutsoudaki, M. Krsek, A. Rodger, J. Agric. Food Chem. 53 (2005) 7681-7685

[19] M. A. ElSohly, D. Slade, Life Science 78 (2005) 539-548

[20] K.T. Fitzgerald, A. C. Bronstein, K. L. Newquist, Topics in Compan. An. Med. 28 (2013) 8-12

[21] T.F. Bachiega, J.P.B. de Sousa, J.K. Bastos, J.M. Sforcin, Natural Product Research 27 (2013) 1646-1650

[22] M.A. Besten, V.C.G. Jasinski, Â. de G.L.C. Costa, D.S. Nunes, S.L. Sens, A. Wisniews Jr., E.L. Simionatto, D. Riva, J.B. Dalmarco, D. Granato, J. Braz. Chem. Soc. 23 (2012) 1041-1047

[23] E.C. Wendt, The Medical Record 3 (1888) 597-598

[24] P. Le Couteur, J. Burreson, “Napoleon’s Buttons“, TarcherPenguin, Nova Iorque, 2003

[25] L.S. Goodman, A. Gilman A. (eds.), "The Biological Basis of Therapeutics”, MacMillan, London, 1970

[26] J. Emsley, “Molecules at an Exhibition”, Oxford University Press, Oxford, 1998

\section{ACONTECE}

Na ChemistryViews, a revista online da ChemPubSoc Europe (associação de dezasseis sociedades europeias de Química em que se inclui a SPQ), pode encontrar uma entrevista com um professor do Instituto de Química Orgânica da Universidade Ruprecht Karls, Heidelberg, que nos conta o que “cozinha” no laboratório e o que cozinha em casa. No laboratório as suas preferências vão para a síntese e estudo de materiais com sistemas $\pi$ conjugados, tais como fluoróforos cruciformes; em casa, o seu prato aromático favorito é rabo de boi com funcho. A entrevista e a receita estão disponíveis em: //www.chemistryviews.org/details/ezine/4880511/Whats_Cooking_in_Chemistry_Uwe_Bunz.html

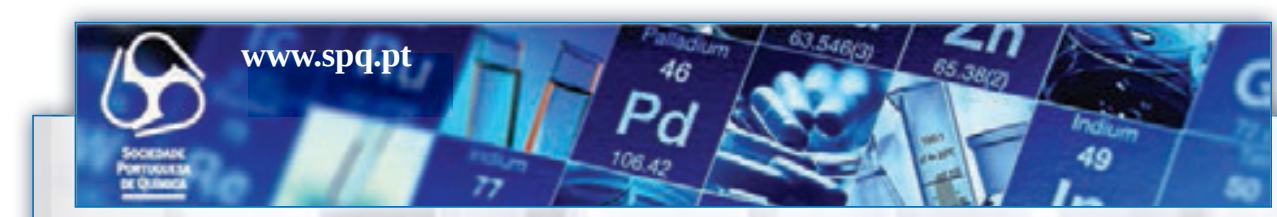

Torne-se Sócio da Sociedade Portuguesa de Química e beneficie de:

- Pertencer a uma comunidade científica dinâmica;

- Receber o boletim "QUÍMICA";

- Descontos nos Encontros promovidos pela SPQ;

- Descontos nas publicações da SPQ;

- Protocolos assinados entre a SPQ e outras entidades;

- Participar na promoção da Química;

- Apoiar uma Sociedade Científica. 
